\title{
O COOPERATIVISMO DE LEITE DA AGRICULTURA FAMILIAR NO SUDOESTE DO PARANÁ: DO PROCESSO ORGANIZACIONAL À CRISE
}

Cooperativism of milk of family agriculture in southwest Paraná: from the organizational process to the crisis

Leomar Rippel

Adilson Francelino Alves

Clério Plein 


\title{
O COOPERATIVISMO DE LEITE DA AGRICULTURA FAMILIAR NO SUDOESTE DO PARANÁ: DO PROCESSO ORGANIZACIONAL À CRISE
}

\author{
Cooperativism of milk of family agriculture in southwest Parana: from the \\ organizational process to the crisis
}

\author{
Leomar Rippel \\ Adilson Francelino Alves \\ Clério Plein
}

\begin{abstract}
Resumo: O objetivo deste artigo é fazer uma análise do surgimento, ascensão, apogeu e crise das cooperativas de leite da agricultura familiar no Sudoeste do Paraná. O método de investigação consistiu de pesquisa bibliográfica associada às entrevistas semiestruturadas com atores estratégicos do processo. Como principais resultados destaca-se que as cooperativas de leite surgiram em meados dos anos 1990 como uma forma de fortalecimento da agricultura familiar no mercado do leite, em franca expansão no período. No seu apogeu, em 2009 havia 27 cooperativas atuando na região Sudoeste do Paraná, número reduzido para 11 em 2016. Entre as explicações para a crise estão fatores relacionados à organização (planejamento e gestão) associado à concorrência com grandes empresas, o que resultou em dificuldades de fidelização dos associados.
\end{abstract}

Palavras-chave: Cooperativismo; Agricultura Familiar; Desenvolvimento Rural; Crise.

\begin{abstract}
The objective of this article is to analyze the emergence, rise, apogee and crisis of the family farming milk cooperatives in the Southwest of Paraná. The research method consisted of a bibliographical research associated to semi-structured interviews with strategic actors of the process. As main results it is highlighted that the milk cooperatives appeared in the mid-1990s as a way of strengthening family farming in the milk market, which was in sharp expansion in the period. At its peak, in 2009 there were 27 cooperatives operating in the Southwest region of Paraná, a figure reduced to 11 in 2016. Among the explanations for the crisis are factors related to the organization (planning and management) associated with competition with large companies, which resulted in difficulties of loyalty of members.
\end{abstract}

Keywords: Cooperativism; Family farming; Rural Development; Crisis.

JEL: Q1; Q13 


\section{Introdução}

Esse trabalho tem por objetivo fazer uma análise do surgimento, ascensão, apogeu e crise do cooperativismo de leite da agricultura familiar no Sudoeste do Paraná. Para tanto, julgamos necessário dividir o trabalho em três partes, sendo a primeira uma breve análise histórica do surgimento do cooperativismo na Inglaterra, sendo uma necessidade material de subsistência por parte dos tecelões ingleses, que estavam imerso num conjunto de mudanças de ordem econômica, social e política na consolidação do capitalismo. Em seguida, será analisada experiência do cooperativismo solidário da agricultura familiar no Sudoeste do Paraná, inicialmente com o ramo crédito, porém nos focamos nas Cooperativas de Leite da Agricultura Familiar com Interação Solidária (CLAFs). Por fim, o foco é o processo de crise destas cooperativas que se instaura no período recente, enfatizando os problemas relativos ao planejamento e gestão.

Em relação a metodologia utilizada nesse trabalho, além de dados de pesquisas bibliográficas realizadas sobre a temática, foram de grande relevância as entrevistas realizadas com três atores sociais que tiveram e estão envolvidos nesse processo. Uma é ex-lider do cooperativismo de leite da agricultura familiar, o segundo ainda exerce um papel de liderança e outro é um dos assessores estratégicos do cooperativismo da agricultura familiar. As entrevistas são semiestruturas a fim de não deixar algo engessado e coletar o máximo de informações possível para problematizações.

\section{COOPERATIVISMO}

O cooperativismo nasceu das necessidades materiais de sobrevivência e da experiência pioneira dos famosos tecelões de Rochdale, um povoado situado no distrito industrial de Lancaster, no Oeste da Inglaterra. Os tecelões desempregados foram motivados a se unirem contra as adversidades impostas pela conjuntura socioeconômica em que se encontravam, formando uma cooperativa. Do ponto de vista institucional, este conceito era novo, porém do ponto de vista prático era antigo (THOMPSON, 1998).

É nesse sentido, que o conceito de cooperativismo resulta originalmente do associativismo, ou seja, uma associação de pessoas ou grupos sociais com sentido de identidade, solidariedade ou colaboração, sendo possível observar esse fenômeno tanto nas famílias quanto em empresas, escolas e comunidades (FRANTZ, 2003). De acordo com Pereira:

O cooperativismo utilizará frequentemente (pelo menos em suas origens) o conceito de comunidade, uma vez que ele surgirá com a justificativa de combater as transformações causadas pelo avanço do capitalismo. Originados no interior de associações de operários e camponeses europeus partidários de um conjunto de diferenciado de ideologia de caráter socialista, os primeiros (sic) cooperativas buscavam uma saída para resolver (ou ao menos minimizar) os problemas decorrentes da Revolução Industrial, agravadas no século XIX. (2012, p. 31-32).

Dessa forma, as primeiras experiências de trabalho cooperativo nascem como "uma alternativa econômica a situações históricas específicas, sendo reconhecido como um dos mais eficientes instrumentos de desenvolvimento e de possível transformação social” (DUARTE, 1986, p. 13). A Revolução Industrial, ocorrida na Grã-Bretanha foi para o historiador Eric Hobsbawn o mais importante processo revolucionário no mundo, desde a invenção da agricultura e das cidades, Estado que 
possuía os fatores fundamentais para o advento de tal fenômeno, como o "lucro privado e o desenvolvimento econômico [...] como os supremos objetivos da política governamental” (HOBSBAWN, 1997, p. 45-46).

É nesse cenário que o cooperativismo nasce, como forma de resistência à situação de miserabilidade que muitos europeus viviam:

O movimento social pela organização cooperativa não é um bloco único. Trata-se de um movimento que toma formas e sentidos de organização, segundo as estruturas sociais, as concepções políticas, as categorias econômicas as nacionalidades e as crenças religiosas, as diferentes concepções e interpretações do sentido da cooperação. (FRANTZ; HILGERT; CORRÊA, 2006, p. 30).

De acordo com Frantz (2003), a iniciativa dos tecelões de Rochdale, em 1844, é considerada a primeira experiência do cooperativismo moderno, sendo uma das iniciativas mais marcantes da história do moderno cooperativismo, incorporando ideias e valores sociais da época, tais como: solidariedade, autoajuda, liberdade, democracia, equidade, altruísmo e progresso (2003, p. 18).

A maioria dos teóricos do cooperativismo tem afirmado que o fenômeno do movimento cooperativo moderno se pauta nos interesses das relações de trabalho humano, em contrapartida, portanto, dos interesses do capital. Dentre eles, podemos destacar Frantz (2003), afirmando que: "O movimento cooperativo, como fenômeno da modernidade, tem a ver com a defesa do interesse do trabalho humano contra os interesses do capital" (2012, p. 12). E ainda segundo o mesmo autor:

As formas precursoras de cooperativismo moderno constituem-se, principalmente, por meio da ajuda mútua, com a finalidade de atender, diretamente, as necessidades de seus membros pela produção e conservação de alimentos. Constituem-se também expressões de reações das pessoas e grupos sociais diante dos problemas sociais do mundo do trabalho. (FRANTZ, 2003, p. 16).

Por sua vez, o movimento do cooperativismo da agricultura familiar e da economia solidária no Sudoeste do Paraná está relacionado diretamente à forma de ocupação histórica e geográfica regional, da forma de apropriação da terra, da estrutura fundiária e acima de tudo da experiência histórica de resistência às adversidades encontradas pela população local.

Através das mudanças ocorridas no Brasil, a partir dos anos 1980, que trouxeram diversas alterações na agricultura brasileira, como os processos de abertura econômica neoliberal e a desregulamentação de diversos setores da economia, ocorreram impactos significativos na produção dos agricultores familiares, para Gehlen:

[...] as transformações ocorridas no âmbito internacional, baseadas em uma nova racionalidade política e econômica, que prevê a redução das atribuições estatais e o aumento de poder dos agentes econômicos, através de um processo gradativo de liberalização de mercados e desregulação da atividade disciplinadora dos Estados no campo da economia da política e do social, impuseram uma nova dinâmica operacional ao complexo agroindustrial de laticínios no Brasil. (2000, p. 122).

Acreditamos que esse movimento está relacionado de forma direta com as condições materiais de existência desses grupos familiares. É nesse cenário que se inicia um movimento dos agricultores familiares para a constituição de mecanismos 
de defesa de seus interesses, com a formação das cooperativas da agricultura familiar com interação solidária, a começar pelo processo organizativo do ramo no que se relaciona ao crédito.

\title{
2.1 O COOPERATIVISMO DE CRÉDITO SOLIDÁRIO NO SUDOESTE PARANAENSE E SUAS EXPERIÊNCIAS PARA OUTROS RAMOS DO COOPERATIVISMO
}

Nesse item, abordaremos o processo histórico de constituição do CRESOL e logo após apresentaremos a constituição das cooperativas de leite, uma vez que, em nosso entendimento, elas são consequência das experiências bem-sucedidas das cooperativas de crédito. Nessa perspectiva, em 1989, através da ASSESOAR (Associação de Estudos e Orientação Rural), os recursos da ONG alemã MISEREOR ${ }^{1}$ foram canalizados para financiar um projeto intitulado Fundos de Crédito Rotativo (FCR), cuja finalidade era fomentar o associativismo.

Devido às limitações financeiras, e por conta das inúmeras dificuldades dos agricultores familiares em acessarem crédito para o financiamento da produção em suas propriedades, é na década de 1990 que se começa a pensar na organização associativa e coletiva dos agricultores familiares no Sudoeste do Paraná. Como consequência dessa capacidade organizativa acumulada, em decorrência dessa experiência, em 1995, foi constituída a CRESOL (LANNOY, 2006). O crédito foi o primeiro ramo das cooperativas da agricultura familiar a se organizar, como infere um ex-líder do cooperativismo:

\begin{abstract}
Então, nos anos noventa que começou a se pensar mais no crédito por conta do Banco do Brasil, que era o que financiava, né. E o banco do estado, eles começaram a cortar o crédito dos agricultores. Vinha um volume pra agricultura, eles destinavam pra meia dúzia e não tinha mais dinheiro. E, aí, se começou a se preocupar em criar um [...] fundo de crédito rotativo [...] que nós pegamos oitocentas mil sacas de milho da Alemanha. E, daí, fomos e fomos emprestando, mas era informal, né. (EX-LÍDER DO COOPERATIVISMO DE LEITE SOLIDÁRIO 6, MUNICÍPIO DE RENASCENÇA).
\end{abstract}

Notamos pelas palavras do entrevistado acima que existiam recursos para o financiamento agrícola. No entanto, poucos eram contemplados, deduzimos, a partir do exposto, que as instituições financeiras tinham receio de conceder crédito para a agricultura familiar, pois compreendiam que os riscos de inadimplência eram maiores entre esses, em relação aos médios e grandes proprietários. Outra informação interessante fornecida pelo entrevistado é a relação de confiabilidade, pois a confiança foi e é um valor importante entre os agricultores, já que os recursos tomados por empréstimo da Alemanha foram informalmente direcionados, portanto os riscos existiam, mas a confiança se tornou um valor universal e acabou se sobressaindo em relação à desconfiança.

\footnotetext{
${ }^{1}$ Organização episcopal alemã para cooperação e desenvolvimento no combate à pobreza, suas atuações são voltadas para África, Ásia e América Latina.
} 


\subsubsection{O processo organizacional do cooperativismo de leite da agricultura familiar}

É importante ressaltar, nesse momento, que as nossas interrogações sobre a sustentabilidade, a médio e longo prazo, e o futuro do cooperativismo da agricultura familiar do ramo do leite, começaram em 2009, quando trabalhamos na assessoria de expansão da UNICAFES, entidade que representa todos os ramos das cooperativas da agricultura familiar e economia solidária.

Primeiramente, pensar em constituir cooperativas no início da década de 1990, quando há poucos anos houvera uma crise enorme no cooperativismo, não foi tarefa fácil, o que podemos atestar na fala, a seguir, do mesmo ex-líder do cooperativismo solidário: “[...] bom, falar em cooperativa na época era difícil, porque tinha quebrado as cooperativas, e até pela oficina que tinha feito com que isso quebrasse" (EX-LÍDER DO COOPERATIVISMO DE LEITE SOLIDÁRIO 6, MUNICÍPIO DE RENASCENÇA). As entidades dos movimentos sociais populares sempre foram muito atuantes no Sudoeste do Paraná, assim, a contribuição dessas organizações foi de grande importância para o início do cooperativismo da agricultura familiar:

[...] nós tínhamos um conselho da qual eu fazia parte pelo sindicato dos trabalhadores, né, o das as entidades, inclusive a (CNBB) participava, né, como também integrante do conselho. E isso foi dando certo, daí que surgiu a ideia de nos criar uma instituição financeira pra pegar recurso público, né. (EX-LÍDER DO COOPERATIVISMO DE LEITE SOLIDÁRIO 6, MUNICİPIO DE RENASCENÇA).

De modo concomitante ao processo de constituição das cooperativas de crédito e, percebendo que a experiência fora bem-sucedida, começa-se um diálogo em torno da possibilidade de organizar as cooperativas de produção de leite da agricultura familiar. A mesma hostilidade que os agricultores sofriam do mercado em relação ao crédito, eles tinham em relação ao comércio do leite, de modo que, comercializar de forma individual, fragilizava-os frente às empresas de lácteos. Em conversa com o primeiro presidente de uma das CLAF's, evidencia-se o grau de exploração a que eram submetidos os agricultores:

Bom, aí começou constituir as cooperativas de crédito e eu tive a oportunidade de ser o presidente da primeira cooperativa, mas como eu percebia que o leite também estava se firmando como uma viabilidade econômica na região e eram todos individuais e explorados de uma maneira assim igual ou pior do crédito, né. Aí eu falei: não, eu fico fora porque eu quero organizar as cooperativas do leite, né. Então, foi mais fácil porque eu já tinha um modelo de cooperativa de crédito que só mudou para o leite, né. Com isso, a gente começou organizar os agricultores e começamos a constituir as cooperativas. (EX-LIDER DO COOPERATIVISMO DE LEITE SOLIDÁRIO 6, MUNICÍPIO DE RENASCENÇA).

Por conseguinte, em 1998, constituíram-se as primeiras CLAF's nos municípios de Renascença, Dois Vizinhos, Marmeleiro e Nova Prata do Iguaçu, desse modo:

Tanto essas primeiras quatro cooperativas de leite como todas as outras cooperativas formadas posteriormente foram constituídas a partir de um conjunto de pequenos grupos de agricultores organizados por comunidades rurais de cada município, os chamados 'grupos de base'. Toda a concepção pedagógica e o processo organizativo eram promovidos por alguns 
profissionais que prestavam assessoria aos agricultores através desse grupo. A intenção dos técnicos era incentivar a organização de base entre os agricultores, produzindo neles uma mentalidade de serem fortes se estivessem unidos. Por isso, foram estabelecidos canais de discussão entre os grupos, envolvendo também diversos atores - como os ligados a assistência técnica e a extensão rural e ao poder público municipal - já com o intuito de organizar a comercialização coletiva de dar corpo à ideia de uma central. (ESCHER, 2011, p. 212).

Além do trabalho de caráter organizativo/educativo, de formar os grupos por proximidade e relações de confiabilidade, estabelecendo objetivos, metas e estratégias de consenso entre os produtores de leite, havia um trabalho de acompanhamento técnico com os agricultores familiares produtores de leite: "nós fomos constituindo as cooperativas, e foi dando certo, né. A nossa cooperativa era praticamente virtual, no início, né. Porque nós dávamos assistência técnica, organizávamos e negociávamos o leite com as indústria da região" (ENTREVISTA 6).

Percebemos, então, que além do trabalho organizacional havia um trabalho de assistência técnica, de socialização das informações sobre manejo, genética, qualidade do leite e pastagem. Desse modo, havia os grupos nas comunidades, em torno de dez famílias por grupo, que no conjunto do município poderia alcançar o número de 150 agricultores familiares. A negociação ocorria de forma coletiva nas comunidades rurais e cada um deles tinha um coordenador. Os agricultores, reunidos com os representantes da indústria, somavam a quantidade de leite produzida no município e nas reuniões realizavam a negociação do preço de forma coletiva.

Notamos que, representados pelo coordenador do grupo, havia uma participação dos produtores na negociação do leite com a indústria e essa estratégia facilitava tanto o poder de barganha no aumento do preço quanto na logística da empresa, uma vez que a mesma não precisava negociar o preço do produto de forma individual com cada produtor. Portanto, nesse momento, foi uma estratégia viável para ambos os lados, que fica mais clara na afirmação a seguir:

[...] então tinha os grupos nas comunidade. Tipo, dez famílias por comunidade, que no total davam cento e cinquenta agricultores no município. [...] Com um coordenador que somava a quantia de leite que tinha e, daí, o montante geral negociava com a indústria. Nós temos na cooperativa [...] cem mil litros de leite pra negociar o preço. Aí, vinha os coordenadores do grupo negociar com o cara da indústria e era bacana, interessante. $\mathrm{E}$, com isso, a gente começou ganhando um preço melhor, mas quem ia buscar o leite era o caminhão da indústria. (ENTREVISTA 6).

Diante disso, realizando algumas análises sobre as ações que estavam sendo desenvolvidas pelos grupos familiares nas comunidades e aproveitando o acúmulo de experiências de negociação e estratégias, em busca de melhorar o preço do litro de leite, os agricultores familiares constituíram as CLAF's, ou seja, ocorreu a institucionalização formal das ações que já vinham sendo desenvolvidas na prática. Com a constituição das cooperativas de leite, porém, os espaços de decisões que eram de base, transferem-se para grupos mais limitados, constituídos pelos diretores das cooperativas denominadas de singulares.

As cooperativas de leite da agricultura familiar visavam "promover estratégias de organização e de tecnologias a baixo custo, para que os agricultores não fossem excluídos da produção leiteira, visando à venda conjunta do leite, viabilizando um sistema de coleta de leite, além da prestação de assistência técnica" (BRAGA, 2010, p. 52-53), nessa perspectiva: 
Diante da modernização da produção leiteira, em que agricultores descapitalizados têm dificuldades em acompanhar esse processo e também frente à concentração da atividade leiteira pelas grandes multinacionais, o cooperativismo surge como uma forma de organização que pode dar mais autonomia ao agricultor, possibilitando a disponibilidade de financiamentos para investimentos, além da implantação de estratégias que possibilitem renda maior aos agricultores como, por exemplo, a produção de leite a baixo custo. Com base nesses pressupostos e no chamado Cooperativismo de Interação Solidária, com propostas diferentes do chamado cooperativismo de gestão empresarial, é criada a Cooperativa de Leite da Agricultura Familiar (Claf), alicerçando-se no histórico do cooperativismo, associativismo e outras formas de organizações, tanto formais como informais do Sudoeste paranaense. (BRAGA, 2010, p. 47).

De acordo com Escher, “[...] o que, por um lado, serviu para institucionalizar o que antes era eminentemente informal, mas, por outro, foi gradualmente transferindo os espaços de decisão dos grupos de base existente nas comunidades para grupos mais restritos, formados pelos diretores das cooperativas singulares" (2011, p. 212-213). Consequentemente, após a institucionalização das singulares, as ações e as estratégias permanecem as mesmas, porém cada vez mais deslocadas de um diálogo horizontal com a base, e as decisões se tornam cada vez mais restritas e verticais.

Não pretendemos afirmar, nesse estudo, que a criação das cooperativas de leite da agricultura familiar foi negativa para o seu processo organizativo, porém quando as decisões ficam cada vez mais restritas e verticais e, por consequência, mais rápidas, elas podem ser menos duradouras e os demais envolvidos não se sentirem corresponsáveis pelas decisões de seus diretores:

É curioso observar como um intenso processo coletivo de deliberação reflexiva foi sendo constituído e logo em seguida desestruturado [...] Tratouse de uma interessante experiência, que incluiu aprendizado coletivo, resolução conjunta de conflitos e inovação de processos, em que participaram tanto os agricultores cooperativados na produção de leite como os empresários ou representantes de vários laticínios. (ESCHER, 2011, p. 213).

Ao visualizarem que o processo organizativo das cooperativas estava contribuindo de forma significativa para o aumento no preço do leite, bem como na organização dessa cadeia produtiva, em 2003, constituíram o SISCLAF. Esse Sistema, também denominado de Central, dentre outras funções, tinha um papel representativo, organizativo e de interlocução dos debates e estratégias do cooperativismo de leite da agricultura familiar:

Estas cooperativas modificaram a relação que as empresas estabeleciam com os pequenos agricultores, pois os agricultores organizados passaram a encontrar nas cooperativas uma estrutura de apoio e a possibilidade de elevar o preço recebido pelo leite, seja porque as cooperativas criaram a possibilidade de remunerá-los melhor, seja porque as empresas se obrigaram a elevar os preços pagos aos pequenos agricultores, mesmo àqueles que não se encontravam associados aos sistemas cooperativos. As referidas cooperativas, organizadas para atender especificamente os pequenos produtores, denominados de agricultores familiares, [...] foram se expandindo rapidamente pela grande mesorregião Fronteira Sul. (GNOATTO et al., 2010, p. 4). 
Apesar de não problematizarmos essa questão, ponderamos que seja importante ao menos mencionar que em outras regiões do Paraná também foram constituídas outras centrais de cooperativas de leite da agricultura familiar, baseadas no mesmo modelo organizativo do movimento da economia solidária. Podemos citar como exemplo: o Sistema de Cooperativas de Produtores de Leite da Agricultura Familiar (SISCOOPLAF), localizado no município de Cascavel, congregando, em 2011, nove cooperativas na região oeste do Paraná; e a Central Regional de Cooperativas da Região Centro do Paraná (COORLAF), localizada no município Guarapuava, também congrega nove cooperativas. O SISCLAF, que se inicia a partir de 2003, também é fruto de uma articulação e da experiência organizacional coletiva dos agricultores familiares. De acordo com David:

\begin{abstract}
O Sistema Integrado de Cooperativas de Leite da Agricultura Familiar com Interação Solidária (SISCLAF) - é uma articulação de cooperativas municipais, organizadas a partir de fevereiro de 2003, pela necessidade de se desenvolver, planejar e centralizar ações das diversas cooperativas singulares de leite que começaram a formar-se na região a partir dos anos de 1990. Fruto de um processo de construção coletiva, das entidades da agricultura familiar da Região Sudoeste, as cooperativas de leite municipais, chamadas CLAF, vem há pelo menos doze anos atuando na organização da cadeia produtiva do leite. (2009, p. 17).
\end{abstract}

No ano de 2006, a central SISCLAF congregava um número de 15 cooperativas, e essas cooperativas estavam articuladas junto a outras entidades da agricultura familiar em quatro fóruns tais como: Pinhas, Marrecas, Vale do Iguaçu e Fronteira e tinham como objetivo discutir os problemas e deliberar sobre eles: "o pessoal fazia os fóruns das cooperativas, então essas quinze cooperativas estavam divididas em quatro fóruns, onde estes fóruns as cooperativas por proximidades de região se reuniam para discutir seus problemas, então estava montado dessa forma" (LIDER DO COOPERATIVISMO DE LEITE SOLIDÁRIO 8, MUNICÍPIO DE FRANCISCO BELTRÃO).

Percebemos na figura 01 que, em poucos anos, o cooperativismo de leite da agricultura familiar teve um crescimento considerável, tanto que em 2009 o SISCLAF era formado por 27 cooperativas singulares e, em sua maioria, por produtores considerados pequenos, que produziam menos de dois mil litros mensais. Por conseguinte:

\begin{abstract}
O surpreendente crescimento das cooperativas de leite na região Sul do Brasil, e particularmente do Sistema de Cooperativas de Leite da Agricultura Familiar com Interação Solidária (SISCLAF) no Sudoeste do Paraná, parece em alguma medida estar desafiando certas tendências macroestruturais, como a globalização do mercado dos lácteos, a concentração industrial e a captação da matéria prima por grandes multinacionais e a exclusão generalizada de agricultores familiares pequenos produtores de leite, preconizadas pela maioria dos 'estudos de mercados' orientados por abordagens teóricas mais convencionais. (ESCHER, 2011, p. 209).
\end{abstract}

Não restam dúvidas de que o processo organizativo, que se configurou com o surgimento do cooperativismo do leite da agricultura familiar, contribuiu significativamente para o aumento da produção e da produtividade do leite no Sudoeste do Paraná, e, principalmente, para o aumento do preço recebido pelos produtores. Porém, toda essa organização coletiva em torno do cooperativismo da agricultura familiar começa a apresentar dificuldades a partir de 2011, tema que problematizaremos na próxima seção. 
Figura 01 - Organograma da Central SISCLAF em 2009.

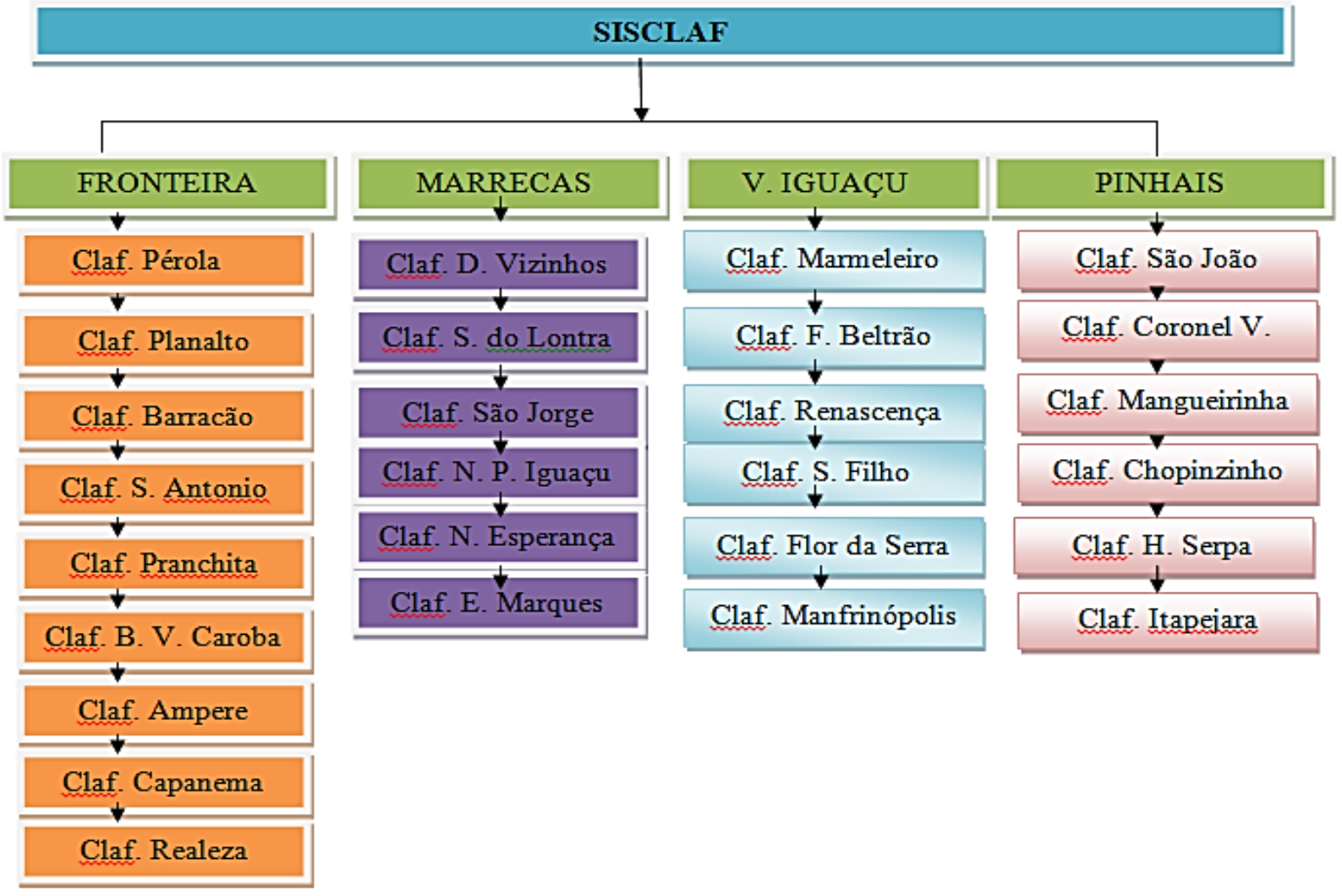

Fonte: Sistema de Cooperativas de Leite da Agricultura Familiar com Interação Solidária (SISCLAF), 2009, adaptado pelo autor do trabalho, 2016.

\subsubsection{Crise do cooperativismo do leite da agricultura familiar no Sudoeste}

Nessa parte do trabalho, focalizaremos as dificuldades enfrentadas pelo mercado do leite na organização do cooperativismo da agricultura familiar no Sudoeste do Paraná. Vale ressaltar que as dúvidas sobre o sistema cooperativo de leite da agricultura familiar no Paraná, já faziam parte de meus questionamentos desde 2009, quando trabalhamos como assessor de expansão da UNICAFES/PR.

$\mathrm{Na}$ ocasião tivemos a oportunidade de visitar 77 cooperativas da agricultura familiar atuantes nos ramos de crédito, produção e comercialização no estado do Paraná. Dentre essas, 27 eram cooperativas de leite vinculadas ao SISCLAF, nove ao COOPLAF e outras nove ao COORLAF. Nesse sentido, através das observações empíricas que tivemos, começamos a nos preocupar sobre a sustentabilidade, a médio e longo prazo, do cooperativismo de leite.

Notamos que, quando começaram a se constituir as cooperativas de leite da agricultura familiar (principalmente a partir do ano 2000), elas se tornaram as indexadoras do preço do leite para as empresas que atuavam nos municípios. Nesse sentido, os preços tiveram um relativo aumento, fazendo com que muitos agricultores familiares se deslocassem de outras atividades e se dedicassem a atividade leiteira, mesmo os que não comercializavam com as CLAF’s eram beneficiados pela atuação das mesmas na região.

É importante ressaltarmos também, que nesse momento muitos agricultores começam a investir cada vez mais na atividade leiteira, resultando numa maior escala de produção e com isso passam a ser assediados pelas empresas privadas. Muitos 
associados das cooperativas acabam saindo desse modelo organizacional, principalmente pelo poder de barganha que tinham devido a sua produção mensal.

A partir do exposto, inúmeros questionamentos surgiram em relação à crise do cooperativismo do leite no Sudoeste do Paraná, tais como: Tal modelo teria entrado em crise devido ao individualismo dos agricultores familiares? Seria uma jogada de mercado das empresas privadas de lácteos que atuavam na região na formação de cartéis de preços para dificultar as ações das cooperativas? Denunciaria a falta de coragem dos agricultores familiares em trabalharem coletivamente, já que a decisão coletiva gera uma responsabilidade coletiva? Demonstra a inexperiência de gestão dos agricultores familiares na condução das cooperativas? Seria a falta de planejamento estratégico na gestão das cooperativas e o descumprimento de sua função no aumento do preço do leite e o repasse para os agricultores familiares, demonstrando a inutilidade de sua existência? E por último, poderia ser bemsucedida uma experiência de cooperativismo solidário com princípios socialistas num sistema de produção e reprodução capitalista?

Esses podem ser questionamentos de inúmeras pessoas que acreditam no cooperativismo solidário como modelo organizacional e de inclusão social dos pequenos agricultores familiares na cadeia produtiva do leite. Contudo, são de suma importância as indagações, reflexões e possíveis críticas à condução desse modelo organizacional, na tentativa de ajudar a apontar caminhos para o futuro do cooperativismo solidário do ramo leite no Sudoeste paranaense.

Através da pesquisa de campo que realizamos, percebemos possíveis deficiências estratégicas no processo organizacional do cooperativismo solidário de leite. Dentre tantos, destacamos a constituição de duas plataformas de resfriamento com recursos do governo federal sem o devido planejamento, uma em Bela Vista da Caroba e outra em Itapejara do Oeste, o que implicou um custo operacional de aproximadamente $\mathrm{R} \$ 20.000,00$ por mês, e os custos independem da quantidade do volume de leite da plataforma. Dessa maneira, quanto menor o volume de leite que passa pelas plataformas, maior será a quantidade de centavos cobrados do produtor para manter os custos operacionais do empreendimento, uma vez que teria dois fretes a pagar, um até a plataforma e outro até as indústrias com as quais as cooperativas comercializavam.

A segunda "falha" estratégica ocorreu logo após a organização dos agricultores produtores de leite em torno das cooperativas. Uma vez que era de suma importância dar início de forma progressiva ao processo de industrialização do leite que passava por dentro das cooperativas, havia propostas de algumas lideranças nesse sentido. No entanto, nas deliberações das cooperativas tal proposta não se concretizou. Partimos do pressuposto de que as dificuldades acima mencionadas resultam da falta de gestão e planejamento, uma vez que os diretores das cooperativas eram agricultores familiares e, com exceção da condução de próprias propriedades, a maioria nunca tivera experiência de gestão.

A constituição do SISCLAF poderia ser uma forma de melhor organizar todas as ações das cooperativas de leite do Sudoeste do Paraná (pelo menos era essa a intenção), porém, constatamos inúmeras dificuldades na organização desse processo. E a principal delas foi o não cumprimento do estatuto que os próprios cooperados constituíram, uma vez que a maiorias das deliberações feitas no coletivo não eram cumpridas pelos diretores quando retornavam para as cooperativas singulares.

Uma dessas decisões foi a de que todas as cooperativas comercializariam o leite pelo SISCLAF via plataformas e deveriam contribuir com $\mathrm{R} \$ 00,1$ por litro para a manutenção do sistema, porém, houve uma cooperativa que não cumpriu tal 
decisão e não sofreu nenhuma forma de sanção, o que motivou outras cooperativas a não respeitarem muitas das decisões coletivas.

Após a decisão deliberada coletivamente sobre a contribuição de $\mathrm{R} \$$ oo,1 para a manutenção do SISCLAF, um dos diretores de uma cooperativa singular, que ajudou a aprovar e deliberar esse assunto, ao voltar para sua cooperativa questionou a contribuição do valor, e o presidente da central decidiu não retê-lo. Sendo assim, a reserva que seria necessária em momentos de crise deixa de existir e, por consequência, o sistema teve dificuldade de se legitimar, pois as decisões coletivas, quando questionadas, eram revogadas pela direção do SISCLAF.

Por conseguinte, as empresas privadas que já tinham experiência de gestão estratégica de mercado, aproveitam as dificuldades organizativas do cooperativismo e começam a traçar estratégias para dificultar a atuação conjunta das cooperativas. Nesse sentido, tudo indica que elas começaram a fazer cartel do preço que pagariam ao SISCLAF e a negociar direto com as singulares, pagando um valor acima do que pagariam na negociação conjunta, inviabilizando assim, as plataformas de resfriamento, conforme identificamos na entrevista abaixo:

[...] aí, essas empresas no mês de maio pra junho, simplesmente, estavam oferecendo exatamente o mesmo valor: 3, 4 centavos mais baixo. Aí, se identificou que elas tinham um cartel baixando o preço para as cooperativas da central não pagariam mais do que aquilo ali. (LÍDER DO COOPERATIVISMO DE LEITE SOLIDÁRIO 8, MUNICÍPIO DE FRANCISCO BELTRÃO).

Dessa forma, diante da inexperiência de gestão dos diretores das cooperativas, da falta de espírito coletivo e das dificuldades da central em organizar o cooperativismo do leite, todo o processo organizativo de mais de uma década começa a ruir:

[...] em abril tem uma entressafra. É o momento que as empresas mais precisam de leite. E naquele momento, a central o SISCLAF estava dizendo que era pra todo mundo passar pela plataforma. Ali já teve o primeiro rachinha, algumas começaram a se negar de entregar. As empresas estavam indo direto nas cooperativas que elas vinham negociando anteriormente, e oferecendo mais do que a comercialização em conjunto. (LÍDER DO COOPERATIVISMO DE LEITE SOLIDÁRIO 8, MUNICÍPIO DE FRANCISCO BELTRÃO).

Pelo fato da comercialização conjunta ser tratado basicamente com empresas do Sudoeste do Paraná, demorou alguns meses até o SISCLAF conseguir negociar com uma empresa de fora, mesmo assim, as empresa da região continuaram pressionando as singulares, tentando convencê-las a venderem direto para as empresas, com a justificativa de que pagariam um valor acima do da central. Além da negociação que as empresas locais tentavam realizar diretamente com as singulares, elas também começaram a disputar aqueles produtores de leite que realizavam investimento na produção leiteira e com isso obtinham um aumento de produção e produtividade.

A maioria dos associados das CLAF's era de pequenos produtores de leite. Em 2009, em torno de $22 \%$ dos produtores de leite no Sudoeste do Paraná estavam vinculados às cooperativas de leite, no entanto, correspondiam a uma produção de apenas $6 \%$ do total do leite produzido na região. Percebemos, então, a importância do cooperativismo para os pequenos produtores de leite, menos capitalizados com uma 
produção de no máximo 100 litros, pois provavelmente seriam excluídos da atividade caso não estivessem vinculados às cooperativas.

Todavia, quando os produtores conseguiam um aumento da produção e da produtividade, a probabilidade dos mesmos se desvincularem da CLAF era grande, tanto que das 27 CLAF's existentes em 2009, apenas 11 estavam com CNPJ aberto, em julho de 2016, e dessas apenas seis estavam operando com leite e uma única estava atuando somente no mercado de merenda escolar.

Portanto, a crise do cooperativismo não resultou apenas da dificuldade de organização em torno do SISCLAF, mas também das cooperativas em fidelizar seus associados, uma vez que as empresas privadas também disputavam produtores de leite com as singulares municipais. Sendo assim, além dos inúmeros problemas de condução da experiência organizacional das cooperativas de leite, acreditamos que o cooperativismo solidário de leite cumpriu com uma função de extrema importância para o que havia se proposto, lutar pela elevação do preço do leite. Tais problematizações serão abordadas na próxima seção.

\section{PROBLEMAS NO PLANEJAMENTO E NA GESTÃO DAS COOPERATIVAS DE LEITE DA AGRICULTURA FAMILIAR OU CUMPRIMENTO DE SUA FUNÇÃO?}

No item anterior, discorremos sobre a grande capacidade organizacional dos agricultores familiares na constituição das cooperativas solidárias de leite, no Sudoeste do Paraná, no intuito de ampliar o seu poder de barganha no aumento do preço do leite. Descrevemos também possíveis equívocos estratégicos que conduziram à atual crise desse modelo organizacional. Sendo assim, interessa-nos nesse momento, discutir a função que a cooperativa exerceu e se, diante da atual organização da cadeia produtiva do leite, há a necessidade material da existência dessas cooperativas.

Na ocasião da constituição do cooperativismo, o objetivo era valorizar o preço do leite, melhorar a situação econômica do produtor, possibilitar a aquisição de equipamentos adequados para o aumento da produção e da produtividade e, acima de tudo, possibilitar o acesso ao conhecimento na atividade leiteira. E o que chama a atenção é o fato de que a grande maioria dos produtores atingiu esses objetivos nos anos de 2009 e 2010, justamente no momento em que houve a maior movimentação de leite pelo SISCLAF, em torno de sete milhões de leite por mês. Sendo assim, o auge das cooperativas tinha sido atingido e a partir desse momento, o sistema organizacional começa a se desintegrar:

[...] quando a central chegou nesse ponto, foi que nem castelo de carta, lá em baixo o pessoal começou a cair fora, e aí começou a desmoronar. Por quê? O que aconteceu? Entre 2009 e 2010, o objetivo de 2003 foi atingido e, aí, a central não tinha mais o que oferecer ao produtor. Vamos se juntar para melhorar o preço? Tá, mas eu já tenho o preço bom, vou me juntar pra quê? No momento em que tenho uma situação estável, pra quê que eu quero cooperativa? Mesmo que seja a cooperativa que deixou ele nessa situação. (LÍDER DO COOPERATIVISMO DE LEITE SOLIDÁRIO 8, MUNICÍPIO DE FRANCISCO BELTRÃO). 
A partir do momento em que a central começa a comercializar todo o leite por dentro do sistema, o trabalho de base que as cooperativas mantinham com seus associados, como o acompanhamento técnico, o manejo, a gestão, etc; será cada vez menos prioritário, principalmente, por conta da "loja", anexa às cooperativas, que a maioria delas passou a operacionalizar. Sendo assim, a função de diretor da cooperativa começa a confundir-se com a de gerente da loja, e a função de técnico passa a misturar-se com a de balconista ou de vendedor da loja.

As lojas apresentam ainda um agravante, não faziam distinções entre sócios ativos e não ativos, desse modo, ao comercializarem com preço reduzido para todos, viabilizavam os negócios fora das cooperativas. Além do mais, como dissemos anteriormente, as indústrias não ofereciam esses serviços aos produtores, dessa forma, a loja da cooperativa contribuía para subsidiar a baixa dos custos. No entanto, as empresas eram as mais beneficiadas, já que não precisavam investir em assistência.

O único contato que o produtor mantinha com a cooperativa era via o motorista do caminhão, ou seja, mantinham uma relação meramente comercial e não como integrantes de uma organização coletiva, que necessitava de decisões também coletivas. Como em muitos casos o trabalho do freteiro era terceirizado, houve situações em que esse decidiu sair da cooperativa e começar a transportar leite para outra empresa. Desse modo, a relação de confiabilidade estabelecida era maior com o freteiro - que em sua saída levou consigo uma parte considerável dos associados -, do que com a cooperativa.

Houve inúmeras ações tanto da cooperativa quanto da central para manter o quadro associado fidelizado. Outra dificuldade encontrada pelas cooperativas novamente gira em torno da gestão, estamos falando da não preparação de um quadro de futuros diretores para gestar a cooperativa, por conseguinte, não foi dado prosseguimento a trabalhos fundamentais de diretores anteriores. É importante salientar que a grande maioria dos cooperados respeitavam o trabalho e as orientações da cooperativa:

[...] os produtores das cooperativas sempre responderam muito bem ao trabalho de campo. Sobre o problema de qualidade, passa um técnico, até mesmo um diretor, mesmo sem conhecimento técnico nas propriedades. A gente tem que melhorar a qualidade do leite, temos que cuidar da higiene, você já vê resultado. Eu acompanhei isso aí há poucos dias em Itapejara, tinha uma identificação da qualidade do leite, e ele foi nas propriedades, na sequência a qualidade do leite melhorou. Quer dizer, o produtor só estava precisando ser chamado a atenção de algum detalhe, alguma coisa; e houve resultado. Realmente teve cooperativas que fecharam, que se distanciaram dos associados, no momento que elas se distanciaram da base a cooperativa não teve sustentabilidade e na sequência a central também não teve sustentabilidade. É como dizem de um castelo de cartas, começou lá em baixo a ruir e vem tudo a baixo. (LÍDER DO COOPERATIVISMO DE LEITE SOLIDÁRIO 8, MUNICÍPIO DE FRANCISCO BELTRÃO).

Embora dentro das cooperativas existam muitos cooperados que as compreendem como um instrumento de fortalecimento coletivo, houve muitas ocasiões em que o agricultor não se identificava com a cooperativa, ou seja, essa não era entendida como um espaço para o processo organizativo e o fortalecimento coletivo dos produtores de leite. Para muitos, não havia nenhuma diferença entre as 
cooperativas e a empresa privada, pois ao invés do preço do leite ser um dos objetivos do processo organizativo, ele se tornou o único.

Além dos associados que buscavam na cooperativa exclusivamente o preço para o leite, também houve inúmeros diretores que buscavam exclusivamente o preço para as cooperativas, tanto na comercialização do leite quanto na compra e venda dos produtos que eram comercializados na loja. Desse modo, a relação se tornou cada vez mais comercial, uma vez que não havia tratamento diferenciado na compra de insumos da loja para associados e não associados.

Algo que nos chamou a atenção em nossa pesquisa de campo foi a falta de experiência na gestão da loja por parte da maioria dos diretores, pois de modo geral eles não estavam preparados para dirigir o empreendimento. Constamos também, de modo bastante perceptível, o desinteresse de muitos desses em realizar as capacitações oferecidas, pelo SISCLAF, a UNICAFES e as Universidades, quanto à gestão, além dos problemas nessa área.

Além da inexperiência no que se refere à gestão dos diretores das singulares, muitos equívocos estratégicos também cometeram os diretores da Central, um dos principais deles diz respeito ao calote de aproximadamente um milhão de reais que a Central levou de uma empresa.

Como um dos principais objetivos do cooperativismo era o preço do leite, os diretores comercializaram boa parte do produto com uma determinada empresa por um preço acima ao das concorrentes. No primeiro mês, a empresa efetuou parte do pagamento, no segundo mês, porém, não efetuou nenhum pagamento para o SISCLAF.

$\mathrm{Na}$ esperança de conseguir receber o dinheiro da empresa, a Central decidiu tomar um empréstimo com a Cresol do montante não pago pela empresa e repassá-lo aos produtores, desse modo, esses não sentiriam o calote. Assim, a Central conseguiu absorver o calote sem atingir as cooperativas e os produtores, contudo, isso ocasionou impactos maiores posteriormente. Esse fato foi amplamente comentado, inclusive por algumas empresas concorrentes, para dificultar a relação entre os associados e a cooperativa.

Para melhor compreendermos a diferença do cooperativismo solidário com as empresas privadas, faz-se necessário trazer para o debate um conceito importante que é a transparência, pois é notório que esse aspecto é um valor importante, mas na relação com o mercado a transparência torna-se um problema.

No jogo do mercado, o acesso transparente aos dados, como o cooperativismo, na medida do possível, tentou fazer, levou que as empresas experientes nas regras desse jogo não tivessem muitas dificuldades para suplantar as estratégias de mercado desenvolvidas pelas cooperativas, como salienta um dos assessores do SISCLAF, das cooperativas:

[...] um problema da central sempre foi alardear aos quatro ventos sua situação, situação financeira. E, assim, se a situação financeira da central estava ruim, todo mundo sabia. Tanto concorrente, entidades parceiras, todo mundo, sempre foi dentro dessa lógica, nunca escondeu isto pra ninguém. Só que num mercado aonde não está preocupado com o que é a empresa e o que é a cooperativa, o que é agricultor familiar, que tem toda uma representatividade, qualquer sintoma de fraqueza é usada contra. Então, ali sofreu um processo enorme de decadência, digamos assim, estava no auge e na hora que deu isso começou a desmoronar mais rápido ainda. Então, não que o processo de diminuição de cooperativa de ter saído agricultor não fosse acontecer, ele ia acontecer de qualquer jeito, só que isso acelerou o processo. 
Talvez levasse dois anos, aconteceu em um ano porque foi influenciado dessa forma. (LÍDER DO COOPERATIVISMO DE LEITE SOLIDÁRIO 8, MUNICÍPIO DE FRANCISCO BELTRÃO).

$\mathrm{Na}$ tentativa de negociar o calote com as empresa, o SISCLAF, acabou adquirindo uma unidade industrial da referida empresa. Porém, era uma unidade extremamente ultrapassada do ponto de vista tecnológico e produtivo, uma vez que, a maioria dos equipamentos era totalmente obsoleto. A central adquiriu essa unidade por $\mathrm{R} \$ 1$ 1.700.000,000, desse modo, liquidou toda a capacidade de operacionalizar uma indústria, pois gastara parte significativa do capital de giro no negócio.

Mesmo com todas as dificuldades, no terceiro mês (em dezembro) de atividade da indústria, houve uma sobra de $\mathrm{R} \$ 150.000,00$. No entanto, esse período do ano é o período de maior produção, não obstante, toda essa sobra foi repassada para os produtores, inflacionando assim $(\mathrm{R} \$ 0,17)$ o litro de leite. Aparentemente foi um bom negócio, porém, nos meses seguintes, além da diminuição do volume de leite, a indústria precisou competir com as empresas que estavam mais preparadas para bancar uma oscilação de preços até que o mercado se equacionasse novamente.

Como percebemos, inúmeras tentativas e esforços foram realizados para a constituição e o fortalecimento organizacional do cooperativismo. Percebemos que em longo prazo a crise se abateu sobre o cooperativismo. Inúmeras dificuldades existem para compreender o que está por trás dessa situação, talvez uma explicação de cunho ideológico seja mais prática, mais fácil e menos dolorida, como colocar a culpa no cenário, nas forças externas do capitalismo e na dificuldade organizacional.

No entanto, ao longo desse trabalho, ficou mais evidente que o ponto fundamental foi a não elaboração de uma estratégia de fases de implementação, ou seja, um processo organizacional que começasse primeiramente com a organização dos produtores, a comercialização coletiva e a constituição das cooperativas singulares. A segunda fase seria a industrialização e a terceira, a constituição do SISCLAF. Desse modo, a primeira fase foi bem-sucedida e a terceira fase foi antecipada, queimando a etapa da industrialização.

As dificuldades e as problemáticas em torno da crise do cooperativismo de leite da agricultura familiar são preocupações constantes dos atores envolvidos, um dos assessores do cooperativismo salienta:

[...] como vencer as transições, diria, dentro da agricultura familiar e o cooperativismo, ser, portando, um meio facilitador dessa transição? As cooperativas de leite se instalaram em momentos de crise. Estabilizou o mercado, mas nós continuamos entendendo as cooperativas como necessárias em momentos de crise e não conseguimos mudar, transitar pra fase 2. Essa é a primeira constatação. (ASSESSOR DO COOPERATIVISMO 10, MUNICÍPIO DE FRANCISCO BELTRÃO).

Um de nossos principais questionamentos era se poderia ser bem-sucedida uma experiência do cooperativismo solidário de autogestão democrática, com princípios socialistas num sistema de produção e reprodução capitalista. Sendo assim, a defesa da importância dos princípios do cooperativismo é inquestionável, mas no caso do cooperativismo solidário de leite no Sudoeste precisam ser encarados de forma mais crítica. Nesse sentido, a defesa da economia solidária e assistencialista com um modelo de gestão descentralizado, sempre foi a principal bandeira de muitas 
lideranças, uma vez que essa era uma forma de se diferenciarem do cooperativismo tradicional.

Porém, o que a história nos reservou (não que concordemos com isso), foi que a autogestão democrática fracassou, ou seja, acreditamos que o fracasso da autogestão democrática aconteceu em função da falta de experiência por parte dos agricultores com esse modelo organizacional.

Portanto, o principal objetivo da negociação coletiva do leite era o aumento no preço recebido pela indústria, talvez isso ajude a explicar os motivos pelos quais o cooperativismo teve um processo de aproximadamente 15 anos de ascensão e após isso um processo de crise. Uma vez que a cooperativa cumpriu a função pela qual foi constituída, após esse aumento do poder de barganha intermediado pela cooperativa, houve um aumento de produção e de produtividade entre os agricultores familiares e, por consequência, os mesmos começaram a depender cada vez menos da organização coletiva e da cooperação, e a maioria começa a negociar o preço diretamente com as empresas.

Para que tivéssemos uma sociedade em que predominasse a igualdade entre todos os seus membros, seria preciso que a economia fosse solidária em vez de competitiva. Isso significa que os participantes na atividade econômica deveriam cooperar entre si em vez de competir. (SINGER, 2002, p. 9).

Portanto, mesmo que o cooperativismo de leite solidário era exaltado retoricamente, se colocando como um sistema contra hegemônico ao cooperativismo tradicional e o capitalismo, ele não passou de um projeto de inclusão dos pequenos agricultores ao capitalismo e suas práticas individualistas.

\section{CONSIDERAÇÕES FINAIS}

Nesse trabalho, analisamos a relevância do processo organizacional dos agricultores familiares em torno das Cooperativas de Leite da Agricultura Familiar e Economia Solidária, com intuito de acessar melhores preços e mercado para a matéria prima. Também percebeu-se as cooperativas com uma ferramenta importante na organização produtiva do leite. Ainda tentou-se compreender os motivos pelos quais esse modelo organizacional do cooperativismo de leite entrou em um processo de crise nos últimos anos. Dessa forma, foram apontados inúmeros problemas de gestão e planejamentos do cooperativismo solidário. Porém, procuramos apontar alguns possíveis caminhos para a superação da crise do Cooperativismo. Consideramos, portanto, que as discussões em torno das problemáticas trabalhadas nesta dissertação não se esgota nela mesmo, muito pelo contrário, acreditamos que ela pode contribuir para outras futuras análises sobre a referida temática. 


\section{REFERÊNCIAS}

BRAGA, L. C. A territorialização da produção leiteira e fumageira na Linha Itaíba, Marmeleiro - PR. 2010. 190 f. Dissertação (Mestrado em Geografia) - Universidade Estadual do Oeste do Paraná, Francisco Beltrão, PR, 2010.

DAVID, A. de. Competitividade das Cooperativas do Sistema de Cooperativas de Leite da Agricultura Familiar - SISCLAF. 2009. 73 f. Trabalho de conclusão de curso (Especialização em Gestão do Cooperativismo Solidário) - Universidade Estadual do Oeste do Paraná, Francisco Beltrão, PR, 2009.

DUARTE, L. M. G. Capitalismo \& cooperativismo no R.G.S. Porto Alegre: L\&PM, 1996.

ESCHER, F. Os assaltos do moinho satânico nos campos e os contramovimentos da agricultura familiar: atores sociais, instituições e desenvolvimento rural no Sudoeste do Paraná. Dissertação (Mestrado em Desenvolvimento Rural) - Universidade Federal do Rio Grande do Sul, Porto Alegre, RS, 2011.

FRANTZ, W. Caminhos para o desenvolvimento pelo cooperativismo. Ijuí: Unijuí, 2003.

; HILGERT, V.; CORRÊA, R. A história do cooperativismo de crédito em Panambi: uma trajetória de 75 anos. Ijuí: Ed. Unijuí, 2006.

GEHLEN, I. Competitividade e identidade do produtor familiar de leite Gaúcho face às inovações tecnológicas e organização da cadeia produtiva. Porto Alegre: UFRGS, 2000.

GNOATTO, A. A. et al. Perspectivas para o cooperativismo de leite da agricultura familiar no Paraná. In: Congresso da Sociedade Brasileira de Economia, Administração e Sociologia Rural, 48, Campo Grande. Anais... Campo Grande: Universidade Católica Dom Bosco, 2010.

HOBSBAWN, E. A era das revoluções. Europa 1789-1848. Rio de Janeiro: Paz e Terra, 1977.

LANNOY, C. de. O Nascimento do sistema CRESOL: a origem de uma inovação organizacional. dez/2006. Disponível em: <http://www.cresol.com.br/site/>. Acesso em: 10 de abril de 2009.

RIPPEL, L. Os atores e as redes de desenvolvimento rural no processo produtivo do leite no Sudoeste do Paraná. 2016. 178f. Dissertação (Mestrado em Desenvolvimento Rural Sustentável) - Centro de Ciências Agrárias, Universidade Estadual do Oeste do Paraná, Marechal Cândido Rondon, 2016. 
PEREIRA, J. F. Elos \& correntes: história do cooperativismo de crédito no Rio Grande do Sul (1902-1930). Porto Alegre: Sescoop/RS, 2012.

SINGER, P. Introdução à economia solidária. São Paulo: Fundação Perseu Abramo, 2002.

THOMPSON, E. P. Costumes em comum: estudos sobre a cultura popular tradicional. São Paulo: Companhia das Letras, 1998.

\section{Sobre o(s) Autor(es):}

\section{Leomar Rippel}

Graduado em História pela Universidade Paranaense (2008), especialização em Metodologia do Ensino de História (2010), mestrado em História pela Universidade de Passo Fundo (2012), Mestre em Desenvolvimento Rural Sustentável pela Universidade Estadual do Oeste do Paraná (2016), doutorando em História pela Universidade Estadual do Oeste do Paraná. Professor da Faculdade de Ampere - FAMPER e da Faculdade de Direito de Francisco Beltrão - CESUL.

Email: leomarrippel@hotmail.com

\section{Adilson Francelino Alves}

Graduado em Ciências Sociais, especialização em sociologia e Sociologia da Educação ambos pela Universidade Estadual de Londrina (UEL) mestrado em Sociologia pela Universidade Estadual de Campinas (UNICAMP) e doutorado em Ciências Humanas pela Universidade Federal de Santa Catarina (UFSC). Atualmente é professor associado da Universidade Estadual do Oeste do Paraná.

Email: adilsonfalves@gmail.com

\section{Clério Plein}

Graduado em Economia Doméstica pela Universidade Estadual do Oeste do Paraná (2000), mestrado (2003) e doutorado (2012) em Desenvolvimento Rural pela Universidade Federal do Rio Grande do Sul com estágio sandwich no Centro de Estudos Sociais da Universidade de Coimbra (Portugal). Professor da Universidade Estadual do Oeste do Paraná.

Email: clerioplein@gmail.com 